\title{
Dampak Sosial Budaya Dari Program Keluarga Harapan Dan Bantuan Pangan Non Tunai Di Kabupaten Gunung Kidul
}

\author{
Sumarni \\ Universitas Gunung Kidul \\ suci.nazla@gmail.com
}

ABSTRAK

Program Keluarga Harapan dan Bantuan Pangan Non Tunai ini adalah salah satu jaminan social yang diberikan pemerintah pusat kepada masyarakat yang terdaftra sebagai keluarga miskin, program ini dianggap oleh pemerintah pusat mampu mengurangi kemiskinan yang ada di Indonesia, pengalokasian APBN untuk program inipun semakin tahun semakin meningkat, dengan adanya anggaran yang besar itu diharapkan memiliki dampak baik secara ekonomi maupun secara sosial, oleh sebab itu maka tujuan dari penelitian ini adalah untuk melihat dampak sosial budaya yang di hasilkan oleh kebijakan ini. Metode penelitian menggunakan metode kualitatif untuk teknik pengumpulan datanya melalui wawancara dan survei online, survei online yang dilakukan dengan cara disebar keseluruh masyarakat Gunung Kidul menggunakan media sosial, adapun yang menjadi sasaran dari survei online ini adalah masyarakat umum yang tidak menjadi Keluarga Penerima Manfaat (KPM) hasil dari penelitian menunjukkan ada beberapa sosial budaya yang mulai goyah (1) budaya kerja keras, tergerus dengan budaya "ngandalke" bantuan dari pemerintah, mareka yang mayoritas buruh harian dahulunya rajin bila ada yang memberikan pekerjaan mereka semangat menyambut pekerjaan tersebut, namun dengan adanya bantuan ini mereka menjadi tidak seperti dulu sebelum mendapatkan bantuan, (2) berkurangnya rasa kebudayaan tipo sliro hal ini dikarenakan masih terdapat penerima manfaat tidak tepat sasaran, sehingga menimbulkan kecemburuan sosial dan ketidak percayaan terhadap pemerintah desa yang dinilai pilih kasih dalam memberikan bantuan.

Kata kunci: Dampak Sosial Budaya, PKH dan BPNT, Jaminan Sosial.

\begin{abstract}
Program Keluarga Harapan and Bantuan Pangan Non Tunai that of the social guarantees given by the central government to people who are registered as poor families, this program are considered by the central government to reduce poverty in Indonesia, the allocation of the National Budget for this program has been increasing every year, With the existence of a large budget, it is expected to have an impact both economically and socially. Therefore, the purpose of this research is to look at the socio-cultural impacts generated by this policy. The research method uses qualitative methods for data collection techniques through interviews and online surveys, online surveys conducted by way of being distributed throughout the Gunung Kidul community using social media, while the target of this online survey are the general public who are not a Beneficiary Family (KPM) the results of the study show that there are a number of socio-cultural that began to falter (1) a culture of hard work, eroded by the culture of "ngandalke" assistance from the government, those who are mostly daily laborers are diligent when someone gives their work the spirit to welcome the work, but with the help this they are not like they used to be before getting help, (2) there is a decrease in the sense of "tipo sliro" culture because there are still beneficiaries who are not on target, causing social jealousy and distrust of the village government which is considered favoritism in providing assistance.
\end{abstract}

Keywords: Socio-Cultural Impact, PKH and BPNT, Social Security 


\section{PENDAHULUAN}

Program Keluarga Harapan (PKH) dan Bantuan Pangan Non Tunai (BPNT) adalah salah satu bentuk jaminan sosial yang diberikan oleh pemerintah pusat kepada masyarakat pra sejahtera, yang dikoodinir oleh Kemeterian Sosial. Pelaksanaan PKH sudah dilaksanakan pada tahun 2007, sedangkan BPNT dilaksanakan sejak dikeluarkan peraturan Presiden nomor 63 tahun 2017 tentang penyaluran Batuan Sosial secara tunai, yang ditindak lanjuti oleh peraturan menteri sosial republik Indonesia Nomor 20 tahun 2019 Tentang Penyaluran bantuan pangan nontunai, didalam peraturan tersebut pasal 1 ayat 4 bahwa yang dimaksud dengan BPNT adalah Bantuan Sosial yang diberikan secara nontunai dari pernerintah yang diberikan kepada Keluarga Penerima Manfaat (KPM) setiap bulannya melalui uang elektronik selanjutnya digunakan untuk membeli bahan pangan yang telah ditentukan di e-warong.

Anggaran yang dialokasikam oleh pemerintah pada program PKH dan BPNT setiap tahun mengalami peningkatan, pada saat pertama dilaksanakan program PKH anggarannya sebesar Rp.508 Miliyar, untuk tahun kedua Rp.767 Miliyar dan pada tahun ke 10 anggarannya mencapai 17.545 .7 dengan jumlah penerima sebanyak 10.000.232. kita dapat lihat dari diagram diabawah ini.

Grafik 1 Perkembangan Dana Bantuan PKH Dari Tahun 2007-2019

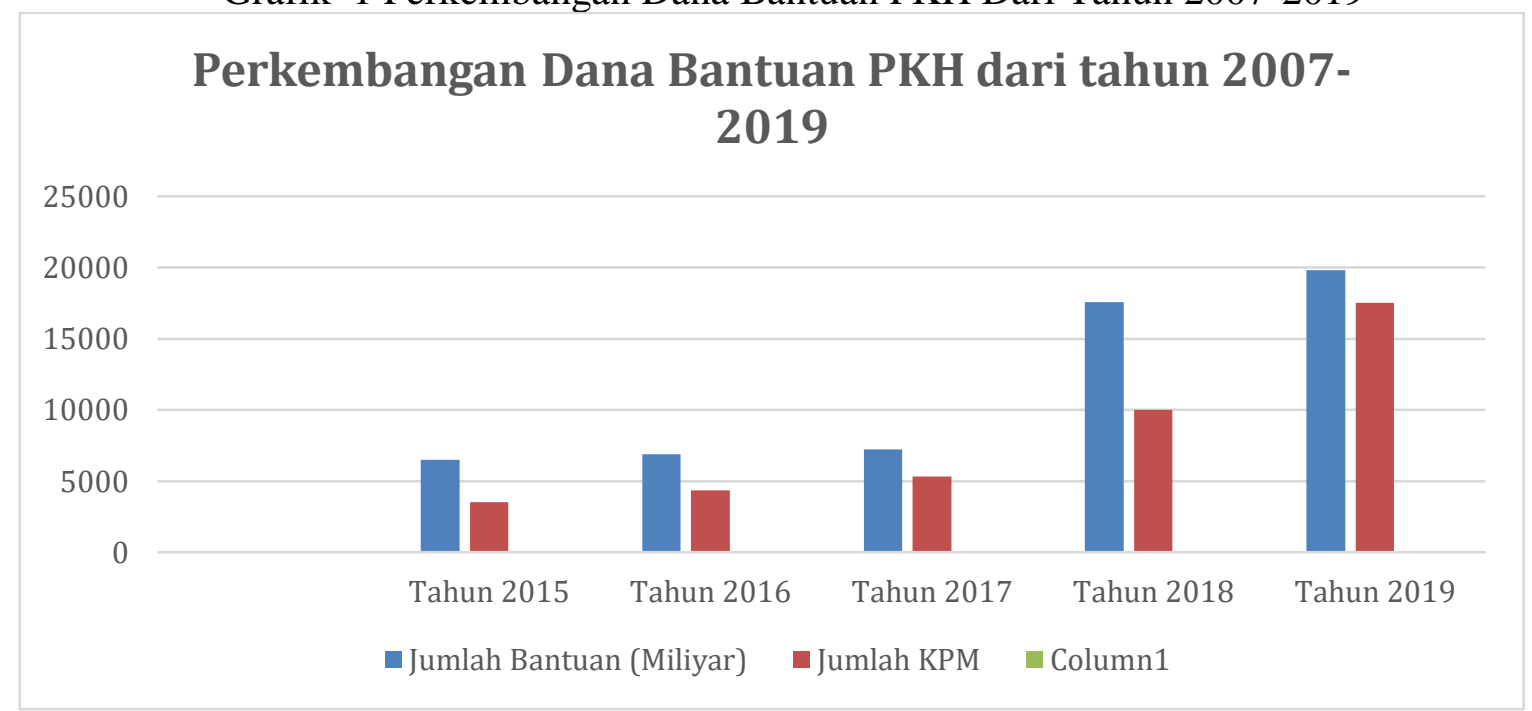

Sumber: Bappenas dan Kementerian Sosial, 2019

Sedangkan untuk program BPNT pada tahun 2019 dana yang dikucurkan pemerintah sebanyak 2,1 Triliun dengan jumlah KPM sebanyak 15,6 juta Keluarga. dengan angka yang tidak sedikit tentu program ini diharapkan memiliki dampak terhadap peningkatan tarap hidup keluarga pra sejahtera (Cristian Perez-Munoz, 2017).

PKH dan BPNT adalah bentuk lain dari Conditional Cash Transfers (CCT), dari beberapa negara menunjukkan bahwa system $C C T$ dinilai sukses dalam pengentasan kemiskinan seperti di Bangladesh yang dipelopori oleh Muhammad Yunus, model yang diterapkan berdasarkan fenomena yang ada di Bangladesh, dimana fenomena yang terjadi adalah kemiskinan yang dialami oleh perempuan-perempuan yang ada disana, mereka tidak memiliki agunan untuk meminjam uang sebagai modal usaha mereka dengan adanya kondisi seperti ini akhirnya M. Yunus meminjamkan uang dan memberdayakan perempuanperempuan yang ada disana (Schwittay, 2018). Brazil dan Mexico juga dinilai mampu 
mengurangi kemiskinan dengan model $C C T$ yang berbeda sesuai dengan kondisi dilapangan setiap negara masing-masing (Soares et al., 2018).

Belajar dari kebijakan yang diterapkan negara berkembang dengan menggunakan sistem jaminan sosial maka kita dapat lihat bahwa kebijakan yang diterapkan dinegara tersebut berdasarkan fenomena yang ada, dengan kultur yang ada sehingga solusi dari permasalahan itu juga berasal dari fenomena dilapangan, kita ambil contohnya di Bangladesh fenomena awalnya adalah permasalahan kemiskinan yang diallami oleh perempuan, sehingga sasaran yang dituju juga perempuan dengan sistem peminjaman modal tidak diberikan cumacuma (Sengupta \& Aubuchon, 2008). Implementasi kebijakan mengenani bantuan sosial di Indonesia sudah dilaksanakan dengan berbagai metode diantaranya dengan menggunakan elektronik yang dinilai efektif dalam pelaksanaan kebijakan (Pramesti, 2019) secara dampak sosial budaya kebijakan ini tentu memiliki dampak tersendiri terhadap perilaku manusia dan kebiasan masyarakat (Taylor et al., 2009).

Tulisan ini ingin melihat dampak yang dihasilkan dari kebijakan ini dari sisi sosial budaya sedangkan untuk melihat dampak secara ekonomi sudah ada beberapa peneliti yang melakukan penelitian dibagian ini, diantaranya adalah Dulkiah1, Sari dan Irwandi (2018) yang berjudul The impact of conditional cash Tranfer (CCT) to socio-economic of poor Familie; a case study yang mereka lakukan di Pesisir Selatan provinsi Sumatera Barat. Hasil penelitian mereka menyatakan:

"In conclusion, research findings have revealed that provision of conditional cash transfer (CCT) has not been effective in improving the socio-economic of poor families in Linggo Sari Baganti districts, Pesisir Selatan regency. The impact of CCT can be seen from several aspects such as status of health, education, economy, distribution of consumption and cost. In health aspect,there is behavior transformation of PKH graduation due to the emergence of the habit in controlling their children to posyanduand checking health to Puskesri. In educational aspect, children are more motivated in school and the parent's awareness increases to their children”. (Dulkiah, Sari dan Irwandu, 2018:38)

Dari penelitian sebelumnya yang melakukan penelitian dampak PKH dalam sisi ekonomi, mereka juga menemukan perubahan pola kehidupan yang dilakukan oleh KPM hal ini dikarekan peraturan yang mengharuskan mereka untuk ikut serta dalam kegiatankegiatan sekolah bagi KPM anak sekolah dan kegiatan posyandu bagi KPM Balita. Temuantemuan diatas maka dalam tulisan ini peneliti ingin menggali lagi lebih dalam dampak sosial budaya yang dihasilkan dari kebijakan PKH dan BPNT diluar "paksaan” yang diterapkan oleh peraturan program ini.

Dampak sosial adalah hasil dari pengaruh baik yang dirasakan, dipikirkan maupun yang dilakukan oleh seseorang dikarenakan oleh kehadiran atau tindakan bahkan yang bersumberkan dari kebijakan sebuah pemerintah Latane (1981) dampak yang bisa kita lihat dari beberapa kondisi atau keadaan baik berupa disfungsi tanggung jawab hingga kemalasan sosial. Dampak sosial seringkali tidak menjadi perhatian dari pembuat kebijakan, bahkan sering dampak sosial yang menjadi tujuan dari kebijakan tersebut tidak sesuai dengan dampak sosial yang ada dilapangan (Wibawa, 2012).

Pemerintah dalam melaksanakan kebijakan seringkali hanya memperhatikan proses kebijakan dan seringkali melupakan dampak dari kebijakan tersebut hal ini karena tidak 
menjadi konsen dari pemangku kebijakan. Dampak kebijakan yang diimplementasikan tentu memiliki dampak positif dan dampak negatif. Untuk mengembangkan teori dampak social maka Latane menggunakan tiga variable:

1) Kekuatan (S) adalah kekuatan yang dimiliki oleh variable baik seseorang maupun lembaga yang dapat mempengaruhi orang lain, dalam hal ini bisa saja orang ini adalah pemerintah, swasta atau pihak-pihak yang memiliki kekuasaan atau kemampuan untuk mempengaruhi, seperti kedudukan, kekayaan, bisa juga kepintara kepintaran.

2) Kedekatan (I) memperhitungkan bagaimana peristiwa itu terjadi dan apakah ada faktor-faktor intervensi lainnya.

3) Jumlah sumber $(\mathrm{N})$ mengacu pada jumlah sumber pengaruh.

Kemudian Bibb membuat formula diantara nya adalah kekuatan sosial menyatakan bahwa $\mathrm{i}=\mathrm{f}(\mathrm{S} * \mathrm{I} * \mathrm{~N})$. Dampak (i) adalah fungsi dari tiga variabel yang dikalikan dan tumbuh ketika setiap variabel meningkat. Namun, jika suatu variabel menjadi 0 atau rendah secara signifikan, dampak keseluruhan akan terpengaruh. Namun semakin banyak penerima manfaat maka semakin sedikit dampak yang dirasakan oleh masing-masing penerima.

Teori dampak sosial dimana teori ini adalah mengeksplorasi situasi sosial sehingga dapat membantu memprediksi hasil dari situasi sosial, sehingga ini dapat membantu pemerintah dalam mengevaluasi sebuah kebijakan baik yang sudah maupun yang belum diterapkan di masyarakat. Pembangunan tidak selalu dikaitkan dengan ekonomi. Pembangunan juga berkaitan dengan sosial, masih menurut pendapat bahwa pembangunan adalah sebuah proses peningkatan kualitas kehidupan manusia. Secara umum pembangunan meliputi 3 aspek yakni pertama meningkatkan level contohnya adalah tingkat pendapatan seseorang, tingkat pendidikan seseorang, tingkat layanan kesehatan kedua menciptakan kondusi kondusif bagi pertumbuhan harga diri masyarakat melalui pembentukan sistem dan institusi sosial, politik dan ekonomi yang mempromosikan martabat manusia dan rasa hormat, ketiga meningkatan kebebasan masyarakat dalam menentukan pilihan yang mereka inginkan tampa ada paksaan dari manapun (Cleary, 2019).

Teori pembangunan adalah teori yang digunakan sebagai acuan untuk membangun sebuah masyarakat. Adapun ide mengenai pentingnya teori pembangunan pada awalnya muncul dikarenaka adanya keinginan dari negara-negara maju untuk mengubah kondisi masyarakat dunia ketiga yang baru merdeka. Pada perkembangannya teori pembangunan berkembang dan mempunyai beragam pendekatan yakni pembangunan struktural, Poststruktural, Postdevelopment, poskolonial, feminisme dan sebagainya. Pendekatan ini saling mengkritik.

Secara umum pembangunan yang dilakukan di Indonesia memiliki dampak karena yang di ususng dari sebuah konsep pembangunan adalah modernisasi, yang manaa modernisasi ini adalah bawaan dari budaya negara eropa dana negara barat. Ada beberapa focus pembangunan yakni ada dibidang pengentasan kemiskinan, penyediaan air bersih, kepedulian terhadap anak dan perempuan, kepedulian terhadap lingkungan dan penyediaan sanitasi. Namun kebijakan yang berdasarkan pembangunan ini seringkali bersifat top-down tidak ada partisipasi dari masyarakat yang menjadi sasaran dari program tersebut. 
Tujuan dari penelitian ini adalah untuk mengetahui dampak sosial budaya dari kebijakan PKH dan BPNT, dan peneliti juga ingin mengetahui dampak social budaya apa saja yang di hasilkan dari kebijakan ini.

\section{MOTODE PENELITIAN}

Dalam penelitian ini menggunakan metode penelitian kualitatif dengan pendekatan deskripstif hal ini berkaitan dengan tujuan penelitian yakni mengekplor dampak yang ditimbulkan oleh program PKH dan BPNT dibidang sosial budaya. Untuk memenuhi penelitian ini maka peneliti mengambil data di kabupaten Gunung Kidul yang terdapat KPM (keluarga Penerima Manfaat).

Adapun jenis data yang digunakan oleh peneliti adalah data primer dan sekunder, untuk mendapatkan data primer peneliti menggunakan teknik wawancara, observasi dan survei online, untuk survei online yang disebarkan melalui sosial media WA, adapun yang menjadi sasaran dari survei online ini adalah warga umum diwilayah kabupaten Gunung Kidul yang tidak menerima bantuan PKH, Adapun pertanyaan nya yang berkaitan dengan penilaian masyarakat umum terhadap perubahan yang di alami oleh KPM. Wawancara dan pengamatan dengan lokus yang sudah ditentukan, kemudian hasil dari wawancara tersebut dianalisis. Sedangkan untuk data sekunder peneliti menggunakan teknik percarian dari berbagai sumber baik dari undang-undang, peraturan presiden dan peraturan menteri yang terkait dengan penelitian ini.

Informan yang diwawancara dalam penelitian ini ada 24 orang yang terdiri dari, 4 aparatur desa, 6 masyarakat umum, 4 pemberi kerja pada KPM, 10 KPM, dan Informan yang disurvei online secara acak berjumlah 52 orang.

\section{HASIL DAN PEMBAHASAN}

Bila kita melihat kembali buku panduan program BPNT maka kita akan melihat kebijakan ini memiliki dampak social budaya, adapun budaya baru yang muncul di KPM diantaranya adalah pertama KPM di "paksa" untuk menggunakan kartu e-warung, kedua KPM dipaksa untuk menghabiskan uang yang mereka terima dengan cara membelanjankannya, ketiga KPM dipaksan menggunakan elektronik, keempat KPM memiliki kebiasaan setiap bulan mendapatkan dana dari pemerintah cuma-cuma tampa harus bekerja keras seperti biasa mereka lakukan sebelum menjadi KPM.

Untuk kegiatan PKH pencairan dana PKH setiap 3x sekali dalam satu tahun setiap jenis KPM menerima dana PKH berbeda-beda, KPM yang layak mendapatkan dana PKH adalah mereka yang dinilai kurang mampu sedang hamil, memiliki anak sekolah tingkat SD,SMP dan SMA serta mereka yang memiliki orang tua yang sudah jompo, temuan dilapangan bahwa mereka menggunakan dana yang mereka dapatkan untuk keperluan seharihari, untuk perubahan sosial yang ditemukan dilapangan ada beberapa temuan, peneliti membaginya menjadi dua bagian:

1. Pertama, adanya perubahan kebiasaan yang mengarah kepada hal-hal positif seperti mereka rajin mengunjungi layanan kesehatan, ikut dalam kegiatan sekolah dan sosialisasi sekolah karena kedua hal itu menjadi salah satu keharusan bagi KPM anak sekolah dan balita. Adapun temuan yang mengarah kepada hal yang bersifat negatif adalah munculnya kebiasaan berhutang dengan jaminan uang PKH. 
2. Kedua meningkatnya rasa kurang semangatnya KPM untuk melakukan peningkatan pendapatan, mereka akan menghabiskan dulu uang yang diterima baru mau melakukan kegiatan nyambut gawe, data ini peneliti dapatkan berdasarkan wawancara dengan mandor-mandor tempak KPM bekerja, mereka menyatakan bahwa sejak "orang nya" mendapatkan PKH dia merasa ada yang hilang dari semangat bekerjanya KPM tersebut.

Hasil survei yang peneliti sebarkan dengan konsep pertanyaan yang dijawab pilihan ganda, hasilnya menunjukkan bahwa $47 \%$ menilai KPM tidak menunjukkan perubahan yang siknifikan dalam bekerja dan ada 35\% yang menilaia tingkan semangat bekerja KPM menjadi rendah setelah mendapatkan bantuan PKH sedangkan ada $18 \%$ yang menyatakan adanya peningkatan semangat kerja dari KPM.

Grafik 2 Perubahan Paradigma Setelah Menjadi KPM

PERUBAHAN SETELAH MENJADI KPM

- tambah rajin $\square$ Biasa saja $\mathbf{M a l a s}$

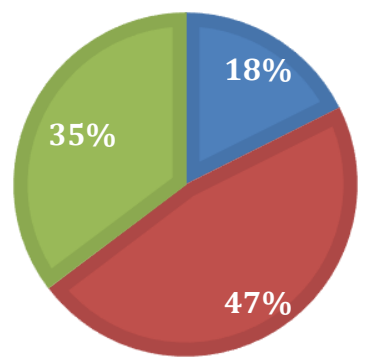

Sumber: Data diolah, 2020.

Disisi lain peneliti juga menemukan ada fenomena baru juga muncul bagi masyarakat yang tidak menerima bantuan yakni program ini menimbulkan kecemburuan sosial, hal ini dikarenakan tidak sedikit data dilapangan menunjukkan bahwa masih banyak KPM yang lebih berada dibandingkan dari masyarakat yang tidak mendapatkan bantuan, sehingga ini menimbulkan kecembuan social yang tidak jarang masyarakat malah membuat grup-grup yang mampu menciptakan gap antara masyarakat.

Dari temuan penelitian dan hasil analisis, peneliti membagi dampak sosial dan budaya dari Program Keluarga Harapan dan Bantuan Pangan Non Tunai di Kabupaten Gunung Kidul menjadi dua bagian. Pertama menjawab seberapa besar damapak sosial yang ditimbulkan oleh kebijakan PKH dan BPNT. Untuk mengetahui jawaban ini maka kita akan menggunakan analisis yang teori dampak sosial sebagaimana peneliti tulisan di kerangka teori. Untuk itu peneliti membaginya menjadi tiga variable.

1. Dampak sosial yang dihasilkan dari kebijakan ini jika dilihat teori dampak sosial yang dibawah oleh Latane (1971) untuk mengukur dampaknya maka kita membagi menjadi 3 variabel Pertama variable kekuatan (S) untuk mendapatkan data lalu merumuskannya maka peneliti melihat seberapa besar pengaruh dalam program ini, berdasarkan data yang ada kita dapat bahwa program ini sangat ditungu-tunggu oleh masyarakat KPM, bahkan ada yang mengandalkan pencairan program ini, KPM akan mengambil BON terlebih dari di toko yang tempat yang ditunjuk oleh pemerintah sebagai pihak yang kerja sama dengan pemerintah, dari data yang didapat ada $80 \%$ 
KPM menunggu dan setelah mendapatkan pencairan mereka istirahat dulu dari pekerjaan mereka. Dimana rata-rata pekerjaan mereka adalah kerja serabutan, dan kuli, dari data yang didapat dan setelah melakukan perumusan maka poin dari kekuatan ini mendapat angka 3 hal ini dikarenakan antusias dari pihak KPM untuk dapat menikmati bantuan ini. Kedua variable Kedekatan (I), data yang kami dapat menunjukkan bahwa kedekatan antara pelaksana program dan penerima program ini ditentukan oleh pendamping masing-masih bahkan tidak jarang pendamping hanya melakukan koordinasi pencairan saja tampa ada pendekatan secara persodal untuk meningkatkan emosi antara pendamping/pelaksana kegiatan dengan KPM, hal ini juga dikuatkan dengan system yang digunakan dalam pencairan dimana program ini menggunakan jasa Bank yang sudah ditunjuk untuk bekerjasama dengan pihak pemerintah. Jadi dalam variable ini maka peneliti memberi point 1 karena lemahnya ikatan antara KPM dan pendamping. Ketiga variable jumlah penerima dari program ini (N) jumlah penerima setiap desa berbeda-beda, untuk desa Kedungpoh jumlah KPM nya adalah $200 \mathrm{KK}$ dan untuk jumlah yang di terima oleh KPM pun berbedabeda adapun jumlah yang diterima oleh KPM ini berbeda-beda tergantung kelompoknya, untuk ada sekolah jumlah nya 200.000 per bulan belum dipotong admin, untuk lansia mendapatkan 300.000 perbulannya, dari data-data yang ada dilapangan maka jumlah penerima tergolong tinggi, sehingga jumlah yang diterima sedikit.

2. Pembahas selanjutmya adalah dampak yang muncul dari kebijakan program pembangunan, dalam pembahasan ini peneliti megkaitkannya denga teori pembangunan. Kita ketahui bahwa conditional cash transfer adalah bentuk dari kebijakan program pembangunan yang ada di negara-negara berkembang, adapun turunan dari kebijakan itu berbeda-beda, di Indonsia kebijakan itu tertuang dalam Program Keluarga Harapan. Dalam ini adalh upaya pemerintah dalam mengurangi angka kemiskinan.

Dampak sosial budaya adalah salah satu unsur yang tersentuh dari kebijakan ini, hal ini diakrenakan kebijakan ini memiliki durasi waktu yang cukup panjang dan tersistem, tentu ini menjadi salah satu penyebab perubahan pola kehidupan masyarakat yang menjadi sasaran maupun yang ada disekitar nya, implementasi kebijakan seringkali tidak melihat dampak yang muncul sesuai dengan yang inginkan atau malah memunculkan kebudayaan sosial yang merusak budaya yang selama ini dianut oleh masyarakat.

Dari teori pembangunan yang telah peneliti bahas sebelumnya menyatakan bahwa, ada tiga aspek yang menjadi tujuan dari sebuah pembangunan yakni pertama meningkatkan drajat atau wibawa masyarakat atau seseorang bila kita lihat dari hasil PKH ini menciptakan kesadaran yang dimiliki oleh KPM untuk ikut serta dalam kegiatan sekolah dan rajin memeriksakan anak mereka di layanan kesehatan, kedua menciptakan kondisi kondusif bagi pertumbuhan harga diri masyarakat melalui pembentukan sistem dan institusi sosial, politik dan ekonomi yang mempromosikan martabat manusia dan rasa hormat, pada kategori ini maka kita temukan bahwa dilapangan PKH juga menciptakan kemunduran dalam memotivasi diri untuk lebih giat meningkatkan taraf ekonominya, disisi lain tingkat kepercayaan masyarakat akan profesionalnya pendamping dalam mendata KPM karena masih ada ditemukannya KPM yang tidak layak mendapatkan bantuan PKH dan BPNT ini. ketiga meningkatan kebebasan masyarakat dalam menentukan pilihan yang mereka inginkan tampa ada paksaan dari manapun. 


\section{PENUTUP}

Kebijakan PKH dan BPNT memiliki dampak sosial budaya pada yang mampu mempengeruhi kebiasaan dan kehidupan KPM maupun masyarakat disekitar KPM, dapat kita lihat bahwa ada dampak social budaya yang muncul yakni munculnya sifat "ngandalke" masyarakat yang mejadi KPM menjadi menurun semangat untuk bekerja nya dikarenakan dia akan mendapatkan bantuan walaupun tidak bekerja, hal ini tentu akan merusak tabiat dari KPM itu sendiri, yang kedua yakni munculnya kecemburuan sosial yang dikarenakan masih adanya salah sasaran dari penerima manfaat itu sendiri.

Kebijakan jaminan sosial ini sangat membantu masyarakat khususnya KPM hal ini tentu pintu peluang bagi pemerintah, untuk mengembangkan kebijakan ini namun tidak terbatas pada pemberian lalu dilepas begitu saja tampa ada pembentukan karakter semangat bekerja, hal ini menjadi salah satu peran pendamping sebagai kaki tangan pemerintah pusat agar KPM tidak tentu harus memiliki kemampuan dalam melakukan pendekatan sehingga masyarakat KPM tidak selalu menjadi objek sebagai penerima fasif, sebaiknya dibantu untuk semangat dalam bekerja tidak menjadikan bantuan PKH menjadi salah satu penyebab untuk bermalas-malasan. Meningkatkan kejelian dan ketelitian dalam melakukan pendataan, memiliki etika administrasi publik sehingga bebas nilai tidak memihak kepada orang-orang yang dekat atau keluarga yang mendata dalam hal ini adalah pendamping.

\section{DAFTAR PUSTAKA}

Bappenas dan Kementerian Sosial, 2019

Cleary, M. (2019). Teori Pembangunan. In Journal of Chemical Information and Modeling.

Creswell, J. (2016). Research desaign pendekatan metode kualitatif, Kuantitatif dan campuran, Pustaka Pelajar, edisi ke empat. Yogyakarta: Pustaka Pelajar.

Cristian, P. M. (2017). What Is Wrong with Conditional Cash Transfer Programs?. Social Philosophy, 440-460.

Dulkiah,Moh.,Avileonardo sari dan Irwandi. (2018). Dulkiah,Moh.,Avileonardo sari dan The impact of condition cahs transfer (CCT) To Socio-Economicof Poor Families; A Case Study. Dulkiah,Moh.,Avileonardo sari dan Irwandi, 2018. The impact of condition cahs transfer (CCT) To Socio- Jurnal Ilmu social Mamangan, volume 7issu 1, January-June :32-39.

Hanlon, Joseph, Hulme, David, and Barrientos. ( 2010. Just Give Money to the Poor: The Development Revolution from the Global South.). Just Give Money to the Poor. Sterling,VA: Kumarian Press.

Indonesia, L. A. (2008). Analisis Kebijakan Publik. Pendidikan dan Pelatihan Kepemimpinan Tingkat III LAN, (p. 32). Jakarta.

Kurniawan, A. ( 2019.). penerima manfaat BPNT 2019 meningkat jadi 15,6 juta keluarga. Jakarta: Kompas.com .

Latane, B. (1981). Social Impact Theory. Harverd: MIT.

Latane, B., Wolf, S. . (1981). The social impact of majorities and minorities. Psychological Review 88, 438-453. 
Michael Todaro Stepen S Smit. (2019). Economic Development. Chicago: Pearson.

Schwittay, A. (2018). Muhammad Yunus. In Celebrity Humanitarianism and North-South Relations. https://doi.org/10.4324/9781315721187-4

Sengupta, R., \& Aubuchon, C. P. (2008). The microfinance revolution: An overview. In Federal Reserve Bank of St. Louis Review. https://doi.org/10.20955/r.90.9-30

Soares, S., Guerreiro Osório, R., Veras Soares, F., Medeiros, M., \& Zepeda, E. (2018). Conditional cash transfers in Brazil, Chile and Mexico: Impacts upon inequality. Estudios Económicos de El Colegio de México. https://doi.org/10.24201/ee.v0i0.387

Treib, P. d. (2014). Handbook Analisis Kebijakan Publik, Teori, Politik dan Metode, . Bandung: Nusa Media.

Taylor, S. E., Peplau, L. A., \& Sears, D. O. (2009). Psikologi Sosial. In Prenada Media Group. Peraturan Menteri Sosial Republik Indonesia Nomor 20 Tahun 2019 Tentang Penyaluran Bantuan Pangan Nontunai

Peraturan Presiden Nomor 63 Tahun 2017 Tentang Penyaluran Batuan Sosial Secara Tunai Pramesti, R. (2019). Impelementasi Bantuan Pangan Non Tunai Melalui Elektronik Gotong Royong Di Kota Tanjungpinang. Spirit Publik.

Wibawa, S. (2012). Kebijakan Publik. Kebijakan Publik Deliberatif. 